\title{
A Experiência de Mães e Pais no Relacionamento com o Filho Diagnosticado com Autismo*
}

\author{
Gisella Mouta Fadda** (D) \& Vera Engler Cury (D) \\ Pontificia Universidade Católica de Campinas, Campinas, SP, Brasil
}

\begin{abstract}
RESUMO - Buscou-se compreender fenomenologicamente a experiência de mães e pais no relacionamento com o filho diagnosticado com autismo. A partir de encontros dialógicos com 11 participantes, narrativas foram construídas, considerando os principais elementos significativos da sua experiência. Os resultados principais foram: (a) o diagnóstico é desencadeador de uma nova compreensão sobre o filho; (b) as mães desenvolvem uma relação de exclusividade com o filho; (c) as mães descuidam de si para cuidarem bem do filho; (d) brincadeiras tornam o relacionamento mais gratificante; (e) a escola é percebida como uma parceira no cuidado do filho. Conclui-se que o relacionamento afetivo entre pais e filhos ultrapassa as limitações que a patologia impõe e pode ser potencializado pela atenção psicológica aos pais.
\end{abstract}

PALAVRAS-CHAVE: autismo, mães e pais, pesquisa fenomenológica, narrativas compreensivas, psicologia humanista

\section{The Experience of Parents in the Relationship with their Child Diagnosed with Autism}

\begin{abstract}
We aimed to understand the phenomenological experience of parents in the relationship with their child diagnosed with autism. From dialogical encounters with 11 participants, we wrote narrative descriptions considering the main elements of relevance in their experiences. Results show that: (a) diagnosis triggers a new understanding of their child; (b) mothers develop a relationship of exclusiveness with their child; (c) mothers neglect themselves to take good care of their child; (d) playing together makes their relationship more rewarding; (e) school is perceived as a partner in the care of the child. Therefore, we concluded that affectionate parent-child relationships go beyond the limitations imposed by the pathology and can be enhanced by psychological care for the parents.
\end{abstract}

KEYWORDS: autism, parents, phenomenological research, comprehensible narratives, humanistic psychology

O Transtorno do Espectro Autista (TEA) está classificado na $5^{\text {a }}$ edição do Manual Diagnóstico e Estatístico de Transtornos Mentais (DSM-5) da Associação Americana de Psiquiatria (2014) como um transtorno do neurodesenvolvimento. Estão incluídas nessa nova categoria pessoas que foram diagnosticadas anteriormente segundo o DSM-IV-TR com "transtorno autista, transtorno de Asperger ou transtorno global do desenvolvimento sem outra especificação" (p. 51), abrangendo, assim, um amplo espectro de sintomas e gravidade variados. Os critérios diagnósticos essenciais apresentados no DSM-5 sustentam-se em dois pilares: Critério $\mathrm{A}$ - déficits persistentes na comunicação social e na interação social em múltiplos contextos; Critério B - padrões restritos e repetitivos de comportamento, interesses ou atividades.
A etiologia mais aceita envolve uma complexa combinação de fatores genéticos e fatores ambientais ${ }^{1}$ que afetam diretamente o neurodesenvolvimento (Chaste \& Leboyer, 2012) no período pré-natal, perinatal ou pós-natal. Diversos autores estão pesquisando como se dão as interações entre os genes associados ao autismo (Constantino et al., 2013; Freitas et al., 2014; Nishiyama, Notohara, Sumi, Takami, \& Kishino, 2009; Sandin

1 Entendem-se como fatores ambientais aqueles causados por agentes infecciosos (como, por exemplo, a rubéola congênita e o citomegalovírus); por agentes químicos (com o uso do ácido valproico na gestação e a exposição à poluição atmosférica); pela idade parental no momento da concepção ou por doenças maternas durante a gestação.

\footnotetext{
* Apoio: CNPq; PUC-Campinas

** E-mail: gisella.fadda@gmail.com

- Submetido: 23/12/2015; Revisado: 12/08/2016; Aceito: 12/10/2016
} 
et al., 2014; Yuen et al., 2015) e a exposição a certos agentes ambientais que servem como gatilho para o desenvolvimento do transtorno (Kong et al., 2012; Raz et al., 2014; Schlickmann \& Fortunato, 2013; Sweeten, Posey, \& McDougle, 2004; Walker et al., 2015; Xu, Jing, Bowers, Liu, \& Bao, 2014).

Nesse contexto, percebe-se que o número de diagnósticos de autismo nos Estados Unidos cresceu exponencialmente na última década, de acordo com dados publicados em 2014 pelo Centro de Controle e Prevenção de Doenças (CDC). Atualmente, a incidência americana aponta para 1 caso de autismo em cada 68 crianças com idade de 8 anos, segundo dados coletados em 2010. Os dados referentes a 2008 indicavam 1 em cada 88 crianças; de 2006, 1 em cada 110; de 2002, 1 em cada 150 (Center for Disease Control and Prevention, 2014).

Não foi encontrada, até o presente momento, explicação para este significativo aumento de casos. Suspeita-se que pode estar vinculado à expansão dos critérios diagnósticos, a diferenças metodológicas nos estudos, ao maior conhecimento sobre o transtorno ou mesmo ao real aumento do número de casos na população (Associação Americana de Psiquiatria [APA], 2014). Na ausência de dados oficiais brasileiros sobre o número de casos de autismo, utiliza-se a estimativa de aproximadamente $1 \%$ da população (APA, 2014), sugerindo que dois milhões de pessoas poderiam ser diagnosticadas com esse transtorno em território brasileiro.

A Interagência do Comitê de Coordenação do Autismo informou que o investimento americano em pesquisas sobre o autismo foi de U\$1,5 bilhão entre os anos de 2008 e 2012 (Interagency Autism Coordinating Committee, 2013). A maior parte dessas pesquisas foi dedicada às possíveis causas $(25 \%)$, à biologia básica $(23 \%)$ e aos tratamentos e intervenções $(20 \%)$, enquanto as pesquisas que abordam a família foram inseridas no item referente a "serviços" em geral, com $8 \%$ de investimentos.
Pesquisando a literatura científica brasileira, foram encontrados estudos que visavam primordialmente validar instrumentos para rastreamento de sinais de risco de autismo para diagnóstico precoce (Baraldi, Rojahn, Seabra, Carreiro, \& Teixeira, 2013; Barbosa \& Fernandes, 2014; Brentani et al., 2013; Costa, Harsányi, Martins-Reis, \& Kummer, 2013; Garcia \& Lampreia, 2011; Machado, Palladino, \& Cunha, 2014; Zanon, Backes, \& Bosa, 2014); propor intervenções e tratamentos (Amato, Santos, Barbosa, \& Fernandes, 2013; Sampaio, Loureiro, \& Gomes, 2015; Teixeira-Machado, 2015) e ter um olhar cuidadoso sobre a família nuclear face aos desafios vividos ao longo da vida (Andrade \& Teodoro, 2012; Dester, 2015; Fernandes, Amato, Balestro, \& MoliniAvejonas, 2011; Misquiatti, Brito, Ferreira, \& Assumpção Jr, 2015; Segeren \& Françozo, 2014; Semensato \& Bosa, 2014; Smeha \& Cezar, 2011; Thiengo, Fonseca, Abelha, \& Lovisi, 2015; Zanatta, Menegazzo, Guimarães, Ferraz, \& Motta, 2014). Nesse contexto, as mães e os pais são, na maioria das vezes, protagonistas no cuidado integral da criança.

A preocupação com a família das pessoas diagnosticadas com autismo no Brasil pode ser constatada na Política Nacional de Proteção dos Direitos da Pessoa com Transtorno do Espectro Autista (TEA), que prevê “o incentivo à formação e à capacitação de profissionais especializados no atendimento à pessoa com transtorno do espectro autista, bem como a pais e responsáveis" (Lei n. 12.764, 2012). Atendendo a essa preocupação, foi desenvolvida uma pesquisa qualitativa com o objetivo de compreender fenomenologicamente a experiência de mães e pais na relação com o filho diagnosticado com autismo.

A experiência humana é aqui compreendida psicologicamente a partir de pressupostos teóricos da Abordagem Centrada na Pessoa, desenvolvida por Carl Ransom Rogers. O conceito de experiência, nesse contexto, vai além de um dado individual, acessível apenas por meio dos sentidos, e volta-se para a natureza relacional, ou seja, para a experiência intersubjetiva.

\section{CONCEITO DE EXPERIÊNCIA}

No livro Tornar-se Pessoa, Rogers (1997) descreve a experiência como algo que ainda não foi nomeado nem classificado, mas que se refere àquilo com que a pessoa entra em contato em dado momento quando relata algo importante de si; é "a experiência de algo desconhecido que deve ser cuidadosamente explorado, mesmo antes que se lhe possa apontar uma designação" (p. 146). A pessoa passa a investigar o que está sentindo e a procurar pelo termo que possa exprimir exatamente o que sente. Ao conseguir dar um significado à experiência vivida, ocorre uma mudança de comportamento, ao que Rogers chamou de "momentos dinâmicos" (p. 147).

Para descrever esse conceito de experiência, Rogers (1997) passa a usar o termo experiencing, um neologismo na língua inglesa que foi traduzido como "vivenciar" e que tenta ressaltar o "caráter imediato da experiência" (p. 484). Pagés (1976), ao discorrer sobre a teoria e a prática de Rogers, refere-se à "experiência imediata" (p. 49-50). Ambas as traduções enfatizam que o termo diz respeito mais a uma qualidade da experiência do que ao próprio conteúdo. Nesse sentido, a experiência é pré-reflexiva ou pré-conceitual e ocorre num fluxo experiencial imediato.

Cabe ressaltar que o termo experiencing foi desenvolvido por Eugene Gendlin (1997), colaborador de Rogers por mais de uma década, e é traduzido como "experienciação" nas obras que discutem especificamente o trabalho de Gendlin. Experienciação é um fluxo de sentimentos concreto e ainda não conceituado, que está presente em todos os momentos. É concreto pelo fato de que a experiência pode ser sentida 
corporalmente como uma vaga sensação, mas que ainda não foi simbolizada, e por isso pode representar algo novo, atualizando a experiência.

Isso não implica simplesmente revelar o que estava escondido, mas formar o significado enquanto se está em contato com a experiência, ou ainda, enquanto se está em contato com o próprio conteúdo de emoções e sentimentos narrados por meio de situações concretas. De acordo com Messias e Cury (2006), essa forma processual de se compreender a experiência humana revela um modo de ser do homem em contínuo processo de vir a ser que se atualiza a partir de relacionamentos interpessoais, ao mesmo tempo em que se coaduna com o conceito de "tendência atualizante" de Rogers.

\section{MÉTODO}

O caminho escolhido para se aproximar da experiência de mães e pais foi alicerçado na fenomenologia de Edmund Husserl, uma vez que se busca recorrer às vivências para conhecer o sentido das coisas, ou seja, sua estrutura essencial.

Segundo Ales Bello (2006), Husserl diz que "não interessa o fato de existir, mas o sentido desse fato" (p. 23). Importa conhecer a realidade tal como é percebida pelo sujeito e não os fatos que podem ser imediatamente verificáveis com medições, mensurações e explicações causais. Para tal, é preciso colocar entre parênteses o que existe, ou seja, o fato (Amatuzzi, 2009).

Colocar entre parênteses - isto é, a époché- é o esforço em suspender o juízo ou a avaliação imediata para se aproximar do sentido. A relação com o mundo é retomada quando se compreende o sentido que a realidade tem para cada um (Amatuzzi \& Carpes, 2010). No contexto da Psicologia, Amatuzzi (2009) aponta que não basta perceber que uma pessoa está com raiva - que seria o fato em si, podendo ser mensurado em alguma escala -, mas é fundamental perceber qual o sentido dessa raiva na relação com o mundo.

$\mathrm{O}$ ato de conhecer, em pesquisas que se intitulem qualitativas e fenomenológicas, inclui necessariamente a presença da subjetividade do pesquisador, que deixa de ser uma ameaça na legitimação dos resultados da pesquisa para ser um elemento constituinte em estudos que versem sobre a experiência humana (Brisola \& Cury, 2016).

\section{A Narrativa como Estratégia Metodológica}

A opção pelo uso das narrativas como recurso metodológico está em consonância com o modo fenomenológico de investigação e a práxis da Psicologia Humanista, pois tanto permite a contextualização e descrição do acontecer clínico quanto permite descrever, compreender e interpretar o fenômeno humano que se deseja conhecer, abrangendo os passos necessários para a redução fenomenológica (Cury, 2015).

Uma pesquisa dessa natureza precisa cuidar da relação a ser constituída nos encontros entre pesquisador e participante, para que possa ser uma abertura ao novo (Szymanski \& Cury, 2004). Dessa forma, o encontro dialógico realizado com cada participante foi ancorado na escuta empática da pesquisadora. O participante, ao comunicar sua experiência tal como é percebida por ele, foi se mostrando e mobilizando a pesquisadora, num movimento em que a experiência vivida de um transformou a experiência vivida do outro.

Após cada encontro, uma narrativa compreensiva foi redigida contendo elementos do vivido da forma como foram compreendidos empaticamente pela pesquisadora no contato com o participante. Nesse sentido, não é necessário se ater ao discurso do participante ou à transcrição literal de sua fala, pois importa compreender os significados da vivência comunicada por ele. Ficar restrito ao que o participante fala literalmente implica o risco de perder a totalidade da experiência. Além disso, Souza e Cury (2015) argumentam que o uso de um gravador pode servir como uma evasiva para afastar o pesquisador da experiência imediata do encontro.

Considera-se que o processo de construção das narrativas seja uma forma apropriada da consciência do pesquisador aproximar-se do fluxo experiencial vivido, uma vez que os significados apreendidos pelo pesquisador, ao serem comunicados, permanecem abertos para que outros pesquisadores possam deles se apropriar, apontando outras possibilidades a partir da intencionalidade da consciência deles próprios.

\section{Construindo as Narrativas}

Na primeira versão da narrativa, a pesquisadora encontrava-se ainda impactada pelo que o relacionamento com o participante lhe causou. O próximo passo consistiu em refinar essas narrativas individuais contando com a participação dos membros do Grupo de Pesquisa do qual a pesquisadora faz parte. A narrativa foi reescrita quantas vezes se fizeram necessárias a fim de contemplar os elementos significativos apreendidos pela pesquisadora, que se tornaram mais claros à medida que ela retomou sua própria vivência do encontro. Concluída essa etapa, uma narrativa-síntese foi construída contendo elementos significativos da experiência de todos os participantes, o que possibilitou a análise e a interpretação fenomenológica da experiência vivida, revelando a estrutura essencial do fenômeno humano em foco.

O processo de construção das narrativas pode causar estranheza à primeira vista entre os pesquisadores mais familiarizados com outros percursos metodológicos. 
Vivenciar um encontro dialógico em pesquisa e, posteriormente, escrever sobre o acontecido para chegar aos dados de pesquisa pode ser comparado à percepção olfativa de um perfume.

A fragrância é descrita pelo perfumista em três momentos: as notas de cabeça (sentidas logo após o frasco ser aberto); as notas de coração (a identidade do perfume que permanece por mais tempo); as notas de fundo (que ajudam na fixação). Contudo, há uma particularidade: a pessoa que vai usar a fragrância. Ainda que determinado perfume tenha a mesma composição, o aroma se modifica em contato com a pele de cada um.

Pode-se considerar que a primeira versão da narrativa representa as notas de cabeça, é a impressão do vivido que ficou na pele do pesquisador. As notas de coração são encontradas nas versões posteriores, ou seja, a identidade única do encontro, cujas nuances podem ser evocadas como um todo quando se volta a atenção novamente para $o$ vivido com o participante, como acontece quando se sente o perfume de algum conhecido e aquela pessoa é evocada imediatamente. Por fim, as notas de fundo, ou o fixador do perfume, representam os elementos mais significativos da experiência individual, identificados quando se passa um tempo trabalhando com as narrativas. A narrativa-síntese pode ser entendida como o desenvolvimento de um perfume universal com as notas mais significativas de cada perfume individual, ou seja, que contém os elementos significativos que emergiram da análise das vivências dos participantes.

\section{Contexto}

Uma cidade de aproximadamente 50 mil habitantes do interior do Estado de Minas Gerais foi o cenário para a realização da pesquisa, após a pesquisadora ter realizado uma palestra sobre autismo com professores de uma escola estadual de ensino fundamental nesse município. Este primeiro contato ocorreu antes da elaboração do projeto de pesquisa e propiciou a escolha dessa instituição por ser considerada uma escola inclusiva, com 11 alunos diagnosticados com autismo matriculados naquela época; e por identificar, na escuta desses professores, a necessidade de oferecer atenção também aos progenitores das crianças.

\section{Os Participantes: Mães e Pais como Protagonistas}

Após receber autorização do Comitê de Ética em Pesquisa com Seres Humanos da PUC-Campinas (Parecer $\mathrm{n}^{\circ}$ 898.700) e da Secretaria de Estado de Educação de Minas Gerais para o desenvolvimento do projeto, a pesquisadora entrou em contato com a escola, que forneceu uma lista com os nomes de 13 crianças diagnosticadas com autismo matriculadas na instituição, seus respectivos progenitores e seus contatos telefônicos. Por ser uma escola de ensino fundamental, os participantes eram pais de crianças com idades de 6 a 10 anos.

A pesquisadora fez contato telefônico com os pais e os convidou para participar da pesquisa, informando-os sobre o objetivo da investigação. Da lista inicial de 26 progenitores de 13 crianças, 11 progenitores ( 7 mães, 2 pais e 1 casal) de 10 crianças ( 6 meninos e 4 meninas) aceitaram participar da pesquisa; e, assim, 10 encontros foram realizados. A partir dos relatos parentais, estima-se que o grau de severidade do Transtorno do Espectro Autista nas crianças variou do nível 1 (leve) ao nível 3 (severo).

\section{Encontro Dialógico}

O primeiro momento do encontro foi destinado a retomar o objetivo e apresentar o termo de consentimento para ser lido e assinado. Logo depois, a pergunta norteadora foi apresentada: "Como é para você conviver com fulano (nome do filho ou da filha)?", deixando que os participantes discorressem à vontade sobre o que os afetava enquanto progenitores de uma criança diagnosticada com autismo, como é proposto em uma entrevista não diretiva ativa, de acordo com Souza e Cury (2015).

Quando os participantes se desviavam do assunto, a pesquisadora não interferia, continuando a ouvi-los com atenção e interesse. Algumas vezes, ela pediu que explicassem melhor algo que não entendera.

Os participantes encerraram o encontro quando acharam conveniente. $\mathrm{O}$ encontro mais breve durou 20 minutos; e o mais longo, 3 horas. Em média, a duração foi de 1h15min.

\section{RESULTADOS E DISCUSSÃO}

O processo experiencial dos participantes, apreendido pela pesquisadora a partir dos encontros e escrito sob a forma de narrativas, desdobrou-se em cinco elementos significativos principais, descritos a seguir.

\section{O Diagnóstico como Desencadeador de uma Nova Compreensão sobre o Filho}

A fim de ilustrar este primeiro elemento, foi incluído um trecho da narrativa-síntese:
[Um] ponto que me chamou a atenção foi o fato de ter ouvido os progenitores comentarem sobre a gravidez, o parto e o desenvolvimento da criança até o diagnóstico de autismo, mesmo que não fosse o tema em questão. Contudo, parecia ser um ponto importante para eles. De alguma forma, ao relembrar esses estágios, esforçavam-se para se apropriar do diagnóstico, talvez tentando integrar as características que já haviam ouvido sobre o autismo e o modo de ser do filho. Após esses momentos de revisitar o processo de desenvolvimento de seu filho, muitos confirmaram e poucos negaram o diagnóstico. Levantaram dúvidas, questionaram causas. É como se 
dissessem mais para si mesmos do que para mim: Tudo isso que falei é o meu filho, e agora?

Durante os encontros, os participantes percorreram todo o caminho desde o período gestacional até o momento em que receberam o diagnóstico, passando a refletir sobre o que representava o autismo na vida deles. Esse aparente desvio do tema proposto representou uma direção importante tomada por eles. Foi necessário que mães e pais reconstruíssem o percurso da própria vivência para que pudessem ressignificá-lo.

À medida que o encontro transcorria, a percepção fragmentada do filho - ora reconhecido como tendo um modo de ser próprio, ora caracterizado como alguém com características provenientes unicamente do autismo - foi cedendo lugar a um reconhecimento desse filho de forma integral. Enquanto os conteúdos emocionais eram descritos, cada progenitor vivenciou, à sua maneira, um processo de significação sobre como foi ter o filho diagnosticado com autismo alguns anos após o nascimento. Com isso, uma nova possibilidade abriu-se: a de uma percepção mais integrada do filho com os sinais clínicos do autismo, abraçando-o em sua inteireza. Isso possibilitou que voltassem à pergunta norteadora, apropriando-se dela: "Como se relacionam com este filho ou esta filha que se apresenta de forma tão estranha $e$, ainda assim, tão próximo, em função dos cuidados que necessitam?".

A apropriação da forma como esse diagnóstico transformaria suas vidas não ficou limitada ao simples transcurso de tempo, tampouco ao recebimento de informações técnicas. De acordo com Bondía (2002), o processo de parar e prestar atenção ao que está acontecendo, nomeado "gesto de interrupção" (p. 24), é necessário para que a experiência seja compreendida e simbolizada. Os participantes, ao falarem sobre o que lhes acontece, puderam trazer à tona o impacto do diagnóstico que ultrapassa a informação em si e desdobra-se em uma nova compreensão sobre o filho.

Esse mesmo percurso foi identificado tanto na pesquisa de Semensato e Bosa (2014), com um casal que acabara de receber o diagnóstico, quanto na pesquisa de Dester (2015), com pais e mães que haviam recebido o diagnóstico do filho há, no máximo, um ano. Os participantes da presente pesquisa tiveram conhecimento do diagnóstico há cerca de três anos em média, ou seja, quando os filhos e filhas tinham aproximadamente seis anos. Esses achados indicam a importância de os pais vivenciarem um processo de construção diagnóstica em que possam falar livremente sobre o assunto com profissionais para que possam dar um significado à sua experiência vivida.

\section{Relação de Exclusividade das Mães com o Filho Diagnosticado com Autismo}

O segundo elemento significativo foi emergindo a partir da percepção da vulnerabilidade do filho ao longo da vida. Em face dessa constatação, um pai dizia temer o futuro, pois previa a total dependência da criança em relação a quem cuidaria dela, enquanto as mães tentavam compensar, no presente, algo que entendiam que o autismo havia subtraído dos filhos. Se faltava aos filhos coordenação motora nas atividades diárias, elas se convertiam em mãos. Se faltavam palavras para se expressarem, elas viravam intérpretes. Se faltavam olhos para pressentirem o perigo, elas se antecipavam aos obstáculos. Se faltava defesa frente aos insultos do mundo, elas se transformavam em escudos. Se faltavam amigos para brincar, elas os cumulavam dos brinquedos que solicitavam.

Os filhos galgavam imediatamente o posto de merecedores incondicionais do desvelo, da atenção e do cuidado materno, numa vigília permanente; a tal ponto que as mães passaram a crer que somente elas eram capazes de entender as criança e delas cuidar, ainda que possuíssem o apoio de alguns membros da família. Nesse momento, revelavam o quanto temiam o futuro. Mostravam-se bastante abatidas ao imaginar a possibilidade de os filhos não serem bem tratados quando viessem a falecer ou quando fossem incapazes de cuidar deles.

Os sentimentos que permeiam as vidas dessas mães são de solidão e isolamento. Queixaram-se do confinamento no ambiente doméstico, seja em decorrência do próprio comportamento dos filhos, que não suportam a movimentação nas ruas; seja para evitarem olhares de reprovação e terem de justificar o motivo pelo qual os filhos agem daquela forma pouco comum. Nesse cenário, uma relação de exclusividade bem particular formou-se entre mãe e filho, afastando, muitas vezes, o pai.

No início, a intermediação da mãe, que serviu como um suporte ao filho, cede lugar a uma relação em que mãe e filho sucumbem a um confinamento imposto pela mãe. Esse tipo de relação, que passou a ser significada como condição inerente a ter um filho com diagnóstico de autismo, acaba por distanciar também essas mães do convívio social, complicando ainda mais a adaptação da criança ao mundo. Entende-se então, que o segundo elemento significativo é o estabelecimento de uma relação de exclusividade das mães com os filhos diagnosticados com autismo, que impõe a ambos um movimento de retirada do mundo. Resultados similares também foram encontrados por Monteiro et al. (2008), Sifuentes e Bosa (2010) e Segeren e Françozo (2014).

A compreensão acerca desse tipo de relação que se forma a partir do convívio com crianças com necessidades diferenciadas é atravessada por fatores subjetivos, e não apenas pelos recursos financeiros da família. Segundo Granato e Aiello-Vaisberg (2002), essas relações são constituídas quando a criança necessita de cuidados especiais em que a "intensa dedicação" (p.89) e o "retraimento em relação ao mundo externo" (p.89) se prolongam às vezes por toda a vida, quando normalmente ficariam restritas apenas aos primeiros meses após o nascimento do filho.

Por outro lado, a sobrecarga dessas mães na atribulada rotina diária parece ser suportada pelo sentimento de amor 
que sentem pelos filhos. São duas faces da mesma moeda: amar o filho acima de qualquer coisa e sentir-se cansada demais com a atenção que esse filho demanda.

Tanto as mães quanto os pais se sentem amados e respeitados pelos filhos, apesar de todos os problemas de comunicação e socialização que vivenciam. É a experiência de amar e sentirem-se amados que também permeia o relacionamento afetivo, tornando suportável a sobrecarga de cuidados. Esses pais e mães prescindem da necessidade de declarações explícitas por parte dos filhos e se conformam com meneios de cabeça, frases sussurradas e toques físicos imprecisos. Aprenderam a compreender a linguagem especial dos filhos e sua forma característica de demonstrar afeto. Essa vivência é oposta àquela encontrada por Verdi (2003) em um grupo de pais de crianças com autismo severo e psicose infantil, que sentem a negação autística dos vínculos como "algo bastante enlouquecedor" (p.111). Cabe esclarecer que Schmidt e Bosa (2003) e Fávero e Santos (2005) perceberam uma tendência atual de se pesquisarem os efeitos psicológicos do comportamento de crianças diagnosticadas com autismo sobre os pais, diferindo de pesquisas anteriores que visavam relacionar alguma característica de personalidade dos progenitores que pudesse predispor o filho ao autismo.

\section{As Mães Descuidando-se de si Mesmas para Cuidarem Bem do Filho}

O terceiro elemento significativo deriva do foco da atenção das mães estar sempre centrado no bem-estar dos filhos, levando-as a esquecerem-se de si mesmas. É um cuidar do outro descuidando-se. A maioria das participantes apresentava-se precocemente envelhecida e poucas verbalizaram o desejo de buscar suprir as próprias necessidades para além de cuidar dos filhos. Terem tempo para si mesmas significaria subtraírem algo a mais das vidas dos filhos, que já são tão sacrificados pelo transtorno.

Inicialmente, o interesse dessas mães em participar da pesquisa relacionava-se a encontrar alguém que as pudesse orientar sobre como cuidar adequadamente dos filhos. Entretanto, a partir da livre expressão, e sem que lhes fosse dada uma ferramenta instrumental de como se conduzirem no encontro, abriu-se a possibilidade para que outros significados pudessem emergir.

Os encontros não exibiram apenas progenitores em seus relacionamentos com os filhos. Os participantes puderam também se revelar como filhos e filhas, como maridos e esposas, como profissionais e donas de casa, como amigos, enfim, como pessoas. Ainda que não tivessem se dado conta do processo subjacente aos conteúdos expostos $-\mathrm{Eu}$ existo, além de ser pai ou mãe de uma criança com sinais de autismo -, havia igualmente um pedido implícito para que se olhasse para eles e para seu sofrimento, pedido este também identificado na pesquisa de Dester (2015), “os pais querem ser escutados e estão sedentos por cuidado” (p. 117).
As mães, em especial, ao se mostrarem gratas pelo tipo de encontro que puderam vivenciar, pautado por uma escuta atenta e empática, sentiram-se mais próximas de si mesmas enquanto pessoas que também precisam de espaço para si. Um estudo realizado com mães que faziam psicoterapia há mais de dois anos mostrou não haver diferenças referentes ao funcionamento familiar, depressão e eventos estressantes, quando em comparação com mães que não tinham um filho diagnosticado com autismo (Sanchez \& Baptista, 2009).

Enquanto isso, uma recente pesquisa na área médica demonstrou que famílias nucleares de crianças com autismo têm telômeros (parte do DNA que se localiza na extremidade dos cromossomos) mais encurtados se comparadas a famílias sem história de autismo (Nelson, Varcin, Coman, DeVivo, \& Tager-Flusberg, 2015). A exposição ao estresse psicológico está associada ao encurtamento acelerado de telômeros, que têm como resultado a aceleração do processo de envelhecimento. Isso pode ser um indicativo clínico do envelhecimento precoce percebido nas mães participantes e que reitera a necessidade de atenção aos familiares, conforme preconizado na literatura científica (Andrade \& Teodoro, 2012; Barbosa \& Fernandes, 2009; Fávero \& Santos, 2005; Fávero-Nunes \& Santos, 2010b; Fernandes et al., 2011; Misquiatti et al., 2015; Rodrigues, Fonseca, \& Silva, 2008; Schmidt \& Bosa, 2007; Sifuentes \& Bosa, 2010; Zanatta et al., 2014).

\section{Brincadeiras Compartilhadas Tornam o Relacionamento com o Filho mais Gratificante}

O quarto elemento significativo foi identificado quando se percebeu que mães e pais relaxavam, sorriam e comentavam sobre alguma brincadeira ou atividade que fizeram junto ao filho, e não pelo filho. Nas vezes em que se dispuseram a brincar ou jogar com o filho, demonstraram alegria ao narrar essas vivências, ainda que tivessem sido iniciadas por pena do filho ser tão sozinho.

Esses momentos especiais parecem aproximá-los da vivência dos pais de crianças sem diagnóstico, levando-os à indagação sobre como conciliar o desgaste diário para que não perdessem a oportunidade de viver esses momentos. Essas experiências significativas, em que existe uma comunicação de mão dupla, proporcionam sentimentos de gratificação e satisfação, como indicou Rogers (2012) no texto "Experiências em comunicação".

Nos momentos de espontaneidade, riso e reciprocidade, as mães ficavam mais presentes, deixando um pouco de lado a ocupação de cuidadoras para estabelecerem um relacionamento mais gratificante com os filhos. Apesar disso, quando elas reclamaram que seus filhos não tinham amigos para brincar, não se reconheceram como sendo capazes de brincar com eles. Untoiglich (2013) e de Moro e Souza (2012) também identificaram uma dificuldade dos progenitores em saber brincar com seus filhos. 
O modo como essas mães estão sempre às voltas com a obrigatoriedade das atividades que o cotidiano lhes impõe em relação aos filhos (alimentação, higiene pessoal, medicação, acompanhamento em consultas médicas e na escola) aproxima-se da vivência identificada na pesquisa de Oliveira (2013) entre profissionais de saúde e pacientes oncológicos. A autora observou que, quando a tecnicidade do cuidado toma conta de todos os espaços da relação profissional da saúde-paciente, pode ocorrer o "esvaziamento da experiência e consequente adoecimento" (p. 125). Dessa forma, supõe-se que, se a mãe permanece apenas na tecnicidade do cuidado do filho, advém o cansaço extremo e o descuido de si mesma. $\mathrm{O}$ estabelecimento de uma relação gratificante por meio de brincadeiras parece ser um caminho para ampliar as possibilidades no relacionamento com o filho.

\section{A Escola como Contexto de Cuidado com o Filho e Percebida como um Elo Confiável com a Comunidade}

Por fim, o quinto elemento foi identificado quando os participantes revelavam que o relacionamento era entremeado por momentos de calmaria ou de descanso quando o filho estava com pessoas que também se interessavam pelo desenvolvimento e bem-estar dele, conforme acontecia quando estavam na escola. A escola, aliás, é praticamente o único local a lhes dar apoio social de forma contínua e diária, ademais do suporte de algumas tias e avós das crianças.

Os progenitores não procuravam uma escola qualquer para que o filho passasse um tempo longe e conseguissem descanso. Importava que fosse uma escola na qual eles percebessem um compromisso com o desenvolvimento do filho e respeito por parte dos funcionários. Uma escola dessa natureza significaria, para eles, uma ilha de descanso. Isso corrobora a conclusão das pesquisas desenvolvidas por Schmidt, Dell'Aglio e Bosa (2007), Fávero-Nunes e Santos (2010a), Smeha e Cezar (2011) e Zanatta et al. (2014), que demonstram como a escola é uma referência importante de apoio social para os pais, muitas vezes vista como um alento. Em contrapartida, a pesquisa de Verdi (2003) com pais de crianças com autismo severo e psicose infantil mostrou que os pais participantes tinham dificuldade de se separar dos filhos e, em alguns casos extremos, chegavam a retirá-los da escola quando os percebiam bem com outras pessoas.

\section{CONSIDERAÇÕES FINAIS}

A relação entre esses pais e mães e seus filhos diagnosticados com autismo inicialmente caracterizou-se por sentimentos de esgotamento, solidão, desamparo e vulnerabilidade. Porém, a exploração dos significados desse relacionamento começou a despontar novos caminhos. O ditado "é caminhando que se faz o caminho" simboliza perfeitamente o sentido que aponta para um com-formar-se, ou seja, formar (a relação) com o outro e não pelo outro. Não há respostas conclusivas para certas questões sobre o autismo. Entretanto, os progenitores pareceram se beneficiar com uma escuta atenta direcionada a eles, e provavelmente se beneficiariam mais se pudessem compartilhar entre si as experiências.
Compreender como é relacionar-se com um filho autista aponta para a importância e a necessidade de outras pesquisas sobre modos de atenção psicológica às famílias de pessoas diagnosticadas com autismo e também sobre a formação profissional do psicólogo e de outros profissionais da área da saúde para oferecer esse cuidado. Pode-se sugerir o desenvolvimento de propostas de intervenção sob a forma de projetos de extensão universitária que disponibilizem encontros grupais entre cuidadores e pais mediados por recursos criativos, como narrar histórias de vida que incluam retomar vivências da própria infância. Essas experiências compartilhadas têm o potencial de promover crescimento pessoal e atualização de significados.

\section{REFERÊNCIAS}

Ales Bello, A. (2006). Introdução à fenomenologia (J. Garcia \& M. Mahfoud, Trad.). Bauru, SP: Edusc.

Amato, C. A. H., Santos, T. H. F., Barbosa, M. R. P., \& Fernandes, F. D. M. (2013). Estudo longitudinal da terapia de linguagem de 142 crianças e adolescentes com distúrbios do espectro do autismo. CoDAS, 25(4), 388-390. doi:10.1590/S231717822013000400015

Amatuzzi, M. M. (2009). Psicologia fenomenológica: Uma aproximação teórica humanista. Estudos de Psicologia, 26(1), 93-100. Recuperado de http://www.scielo.br/pdf/estpsi/v26n1/ a10v26n1.pdf

Amatuzzi, M. M., \& Carpes, M. (2010). Aspectos fenomenológicos do pensamento de Rogers. Memorandum, 19, 11-25. Recuperado de http://www.fafich.ufmg.br/memorandum/a19/ amatuzzicarpes 01
Andrade, A. A., \& Teodoro, M. L. M. (2012). Família e autismo: Uma revisão da literatura. Contextos Clínicos, 5(2), 133142. Recuperado de http://revistas.unisinos.br/index.php/ contextosclinicos/article/view/ctc.2012.52.07/1212

Associação Americana de Psiquiatria. (2014). Manual diagnóstico e estatístico de transtornos mentais: DSM-5 ( $5^{\mathrm{a}}$ ed., M. I. C. Nascimento, trad.). Porto Alegre: Artmed.

Baraldi, G. S., Rojahn, J., Seabra, A. G., Carreiro, L. R. R., \& Teixeira, M. C. T. V. (2013). Translation, adaptation, and preliminary validation of the Brazilian version of the Behavior Problems Inventory (BPI-01). Trends in Psychiatry and Psychotherapy, 35(3), 198-211. doi:10.1590/S223760892013000300007

Barbosa, M. R. P., \& Fernandes, F. D. M. (2009). Qualidade de vida dos cuidadores de crianças com transtorno do espectro 
autístico. Revista da Sociedade Brasileira de Fonoaudiologia, 14(3), 482-486. doi:10.1590/S1516-80342009000400009

Barbosa, M. R. P., \& Fernandes, F. D. M. (2014). Comparação entre os resultados dos protocolos DAADD e ABC de crianças incluídas nos Distúrbios do Espectro do Autismo. CoDAS, 26(3), 208-212. doi: 10.1590/2317-1782/201420130018

Bondía, J. L. (2002). Notas sobre a experiência e o saber de experiência. Revista Brasileira de Educação, 19, 20-28. doi:10.1590/S1413-24782002000100003

Brentani, H., Paula, C. S., Bordini, D., Rolim, D., Sato, F., Portolese, J., . . McCracken, J. T. (2013). Autism spectrum disorders: an overview on diagnosis and treatment. Revista Brasileira de Psiquiatria, 35(1), 62-72. doi:10.1590/1516-4446-2013-S104

Brisola, E. B. V., \& Cury, V. E. (2016). Researcher experience as an instrument of investigation of a phenomenon: An example of heuristic research. Estudos de Psicologia, 33(1), 95-105. doi:10.1590/1982-027520160001000010

Centers for Disease Control and Prevention. (2014). Prevalence of autism spectrum disorders among children aged 8 years Autism and developmental disabilities monitoring network, 11 sites, United States, 2010. Morbidity and Mortality Weekly Report, 56(2), 1-24. Recuperado de http://www.cdc.gov/ $\mathrm{mmwr} / \mathrm{pdf} / \mathrm{ss} / \mathrm{ss} 6302 . \mathrm{pdf}$

Chaste, P., \& Leboyer, M. (2012). Autism risk factors: Genes, environment, and genes-environment interactions. Dialogues Clinical Neuroscience, 3(14), 281-292. Recuperado de http:// www.ncbi.nlm.nih.gov/pmc/articles/PMC3513682/pdf/ DialoguesClinNeurosci-14-281.pdf

Constantino, J., Todorov, A., Hilton, C., Law, P., Zhang, Y., Molloy, E., ... Geschwind, D. (2013). Autism recurrence in half siblings: strong support for genetic mechanisms of transmission in ASD. Molecular Psychiatry, 18(2), 137-138. doi:10.1038/mp.2012.9

Costa, V. B. S., Harsányi, E., Martins-Reis, V. O., \& Kummer, A. (2013). Tradução e adaptação transcultural para o português brasileiro do teste Children's Communication Checklist-2. CoDAS, 25(2), 115-119. doi:10.1590/S231717822013000200005

Cury, V. E. (2015). Narrativas compreensivas sobre sofrimento e cuidado em contextos institucionais. Anais do II Congresso Brasileiro de Psicologia e Fenomenologia e IV Congresso SulBrasileiro de Fenomenologia: Pensar e fazer Fenomenologia no Brasil. UFPR, Curitiba, PR.

Dester, L. L. (2015). Narrativas parentais sobre os sentidos do diagnóstico de autismo do filho. Dissertação de Mestrado, Pontifícia Universidade Católica de Campinas, Campinas, SP. Recuperado de http://www.bibliotecadigital.puc-campinas. edu.br/

Fávero, M. A. B., \& Santos, M. A. (2005). Autismo infantil e estresse familiar: Uma revisão sistemática da literatura. Psicologia: Reflexão e Crítica, 18(3), 358-369. doi:10.1590/ S0102-79722005000300010

Fávero-Nunes, M. A., \& Santos, M. A. (2010a). Itinerário terapêutico percorrido por mães de crianças com transtorno autístico. Psicologia: Reflexão e Crítica, 23(2), 208-221. doi:10.1590/S0102-79722010000200003

Fávero-Nunes, M.A., \& Santos, M.A. (2010b). Depressão e qualidade de vida em mães de crianças com transtornos invasivos do desenvolvimento. Revista Latino-Americana de Enfermagem, 18(1), 1-9. doi:10.1590/S0104-11692010000100006

Fernandes, F. D. M., Amato, C. A. H., Balestro, J. I., \& MoliniAvejonas, D. R. (2011). Orientação a mães de crianças do espectro autístico a respeito da comunicação e linguagem. Jornal da Sociedade Brasileira de Fonoaudiologia, 23(1), 1-7. doi:10.1590/S2179-64912011000100004

Freitas, B. C. G., Trujillo, C. A., Carromeu, C., Yusupova, M., Herai, R. H., \& Muotri, A. R. (2014). Stem cell sand modeling of autism spectrum disorders. Experimental Neurology, 260, 33-43. doi:10.1016/j.expneurol.2012.09.017
Garcia, M. L., \& Lampreia, C. (2011). Limites e possibilidades da identificação de risco de autismo no primeiro ano de vida. Psicologia: Reflexão e Crítica, 24(2), 300-308. doi:10.1590/ S0102-79722011000200011

Gendlin, E. T. (1997). Experiencing and the creation of meaning: A philosophical and psychological approach to the subjective. Evanston, Illinois: Northwestern University Press. (Original publicado em 1962)

Granato, T. M. M., \& Aiello-Vaisberg, T. M. J. (2002). A preocupação materna primária especial. Psicologia Clínica, 14(2), 87-92.

Interagency Autism Coordinating Committee. (2013). IACC strategic plan for Autism Spectrum Disorder (ASD) Research. Recuperado de http://iacc.hhs.gov/strategic-plan/2013/index.shtml

Kong, A., Frigge, M. L., Masson, G., Besenbacher, S., Sulem, P., Magnusson, G., . . . Stefansson, K. (2012). Rate of de novo mutations, father's age, and disease risk. Nature, 488(7412), 471-475. doi:10.1038/nature 11396

Lei n. 12.764, de 27 de dezembro de 2012. (2012). Institui a Política Nacional de Proteção dos Direitos da Pessoa com Transtorno do Espectro Autista. Diário Oficial da União, Brasília.

Machado, F. P., Palladino, R. R. R., \& Cunha, M. C. (2014). Adaptation of the Child Development Clinical Risk Indicators instrument to retrospective parent report. CoDAS, 26(2), 138147. doi:10.1590/2317-1782/2014001IN

Messias, J. C. C., \& Cury, V. E. (2006). Psicoterapia centrada na pessoa e o impacto do conceito de experienciação. Psicologia: Reflexão e Crítica, 19(3), 355-361. doi:10.1590/S010279722006000300003

Misquiatti, A. R. N., Brito, M. C., Ferreira, F. T. S., \& Assumpção Jr, F. B. (2015). Sobrecarga familiar e crianças com transtornos do espectro do autismo: perspectivas dos cuidadores. Revista CEFAC, 17(1), 192-200. doi:10.1590/1982-0216201520413

Monteiro, C. F. S., Batista, D. O. N. M., Moraes, E. G. C., Magalhães, T. S., Nunes, B. M. V. T., \& Moura, M. E. B. (2008). Vivências maternas na realidade de ter um filho autista: uma compreensão pela enfermagem. Revista Brasileira de Enfermagem, 61(3), 330-335. Recuperado de http://www. scielo.br/pdf/reben/v61n3/a09v61n3

Moro, M. P., \& Souza, A. P. R. (2012). A entrevista com os pais na terapia do espectro autístico. Revista CEFAC, 14(3), 574-587. doi:10.1590/S1516-18462011005000075

Nelson, C. A., Varcin, K. J., Coman, N. K., DeVivo, I., \& TagerFlusberg. H. (2015). Shortened telomeres in families with a propensity to autism. Journal of the American Academy of Child and Adolescent Psychiatry, 54(7), 588-594. doi:10.1016/j.jaac.2015.04.006

Nishiyama, T., Notohara, M., Sumi, S., Takami, S., \& Kishino, H. (2009). Major contribution of dominant inheritance to autism spectrum disorders (ASDs) in population-based families. Journal of Human Genetics, 54(12), 721-726. doi: 10.1038/ jhg.2009.105

Oliveira, A. E. G. (2013). A experiência de profissionais da saúde no cuidado a pacientes em ambulatório de quimioterapia. Dissertação de Mestrado, Pontifícia Universidade Católica de Campinas, Campinas, SP. Recuperado de http://www. bibliotecadigital.puc-campinas.edu.br/

Pagés, M. (1976). Orientação não-diretiva em psicoterapia e psicologia social (A. S. Santos, Trad.). Rio de Janeiro: ForenseUniversitária; São Paulo: Universidade de São Paulo.

Raz, R., Roberts, A. L., Lyall, K., Hart, J. E., Just, A. C., Laden, F., \& Weisskopf, M. G. (2014). Autism spectrum disorder and particulate matter air pollution before, during, and after pregnancy: A nested case-control analysis within the nurses' health study II cohort. Environmental Health Perspectives, 123(3), 264-270. doi:10.1289/ehp.1408133

Rodrigues, L. R., Fonseca, M. O., \& Silva, F. F. (2008). Convivendo com a criança autista: sentimentos da família. REME: Revista 
Mineira de Enfermagem. 12(3), 321-327. Recuperado de http:// www.enf.ufmg.br/site novo/modules/mastop_publish/files/ files 4c0e436748b3c.pdf

Rogers, C. R. (1997). Tornar-se pessoa (5 ed., M. J. C. Ferreira \& A. Lamparelli, trad.). São Paulo: Martins Fontes. (Original publicado em 1961)

Rogers, C. R. (2012). Um jeito de ser (M.C.M. Kupfer, H. Lebrão \& Y.S. Patto, Trad.). São Paulo: E.P.U. (Original publicado em 1980)

Sampaio, R. T., Loureiro, C. M. V., \& Gomes, C. M. A. (2015). A musicoterapia e o transtorno do espectro do autismo: uma abordagem informada pelas neurociências para a prática clínica. Per musi, (32), 137-170. doi:10.1590/permusi2015b3205.

Sanchez, F. I. A., \& Baptista, M. N. (2009). Avaliação familiar, sintomatologia depressiva e eventos estressantes em mães de crianças autistas e assintomáticas. Contextos Clínicos, 2(1), 40-50. doi:10.4013/ctc.2009.21.05

Sandin, S., Lichtenstein, P., Kuja-Halkola, R., Larsson, H., Hultman, C. M., \& Reichenberg, A. (2014). The familial risk of autism. Jama, 311(17), 1770-1777. doi:10.1001/jama.2014.4144

Schlickmann, E., \& Fortunato, J. J. (2013). O uso de ácido valproico para a indução de modelos animais de autismo: uma revisão. Jornal Brasileiro de Psiquiatria, 62(2), 151-159. doi: 10.1590/ S0047-20852013000200009

Schmidt, C., \& Bosa, C.A. (2003). A investigação do impacto do autismo na família: Revisão crítica da literatura e proposta de um novo modelo. Interação em Psicologia, 7(2), 111-120. doi:10.5380/psi.v7i2.3229

Schmidt, C., \& Bosa, C.A. (2007). Estresse e auto-eficácia em mães de pessoas com autismo. Arquivos Brasileiros de Psicologia, 59(2), 179-191. Recuperado de http://seer.psicologia.ufrj.br/ index.php/abp/article/viewFile/88/102

Schmidt, C., Dell'Aglio, D. D., \& Bosa, C.A. (2007). Estratégias de coping de mães de portadores de autismo: lidando com dificuldades e com a emoção. Psicologia: Reflexão e Crítica, 20(1), 124-131. doi: 10.1590/S0102-79722007000100016

Segeren, L., \& Françozo, M. F. C. (2014). As vivências de mães de jovens autistas. Psicologia em Estudo, 19(1), 39-46. doi:10.1590/1413-7372189590004

Semensato, M. R., \& Bosa, C. A. (2014). Crenças parentais sobre o autismo e sua evolução. Pensando Famílias, 18(2), 93-107. Recuperado de http://pepsic.bvsalud.org/pdf/penf/v18n2/ v18n2a08.pdf

Sifuentes, M., \& Bosa, C.A. (2010). Criando pré-escolares com autismo: Características e desafios da coparentalidade. Psicologia em Estudo, 15(3), 477-485. Recuperado de http:// www.scielo.br/pdf/pe/v15n3/v15n3a05.pdf

Smeha, L. N., \& Cezar, P. K. (2011). A vivência da maternidade de mães de crianças com autismo. Psicologia em Estudo, 16(1), 43-50. doi:10.1590/S1413-73722011000100006
Souza, G. G., \& Cury, V. E. (2015). A experiência de estudantes sobre a atenção psicológica disponibilizada na universidade: um estudo fenomenológico. Memorandum, 28, 221-239. Recuperado de https://periodicos.ufmg.br/index.php/memorandum

Sweeten, T. L., Posey, D. J., \& McDougle, C. J. (2004). Brief report: Autistic disorder in three children with cytomegalovirus infection. Journal of Autism and Developmental Disorders, 34(5), 583-586.

Szymanski, H., \& Cury, V. E. (2004). A pesquisa intervenção em psicologia da educação e clínica: pesquisa e prática psicológica. Estudos de Psicologia, 9(2), 355-364. Recuperado de http:// www.scielo.br/pdf/epsic/v9n2/a18v9n2

Teixeira-Machado, L. (2015). Dançaterapia no autismo: um estudo de caso. Fisioterapia e Pesquisa, 22(2), 205-211. doi: 10.590/1809-2950/11137322022015

Thiengo, D.L., Fonseca, D., Abelha, L., \& Lovisi, G.M. (2015). Satisfação de familiares com o atendimento oferecido por um Centro de Atenção Psicossocial Infantojuvenil (CAPSi) da cidade do Rio de Janeiro. Cadernos Saúde Coletiva, 23(3), 298-308. doi: 10.1590/1414-462X201500030172

Untoiglich, G. (2013). As oportunidades clínicas com crianças com sinais de autismo e seus pais. Estilos da Clínica, 18(3), 543-558. Recuperado de http://pepsic.bvsalud.org/pdf/estic/ v18n3/v18n3a8.pdf

Verdi, M. T. (2003). Grupo de pais de crianças autistas - tessitura dos vínculos. Revista da SPAGESP, 4(4), 110-114. Recuperado de http://pepsic.bvsalud.org/pdf/rspagesp/v4n4/v4n4a15.pdf

Walker, C. K., Krakowiak, P., Baker, A., Hansen, R. L., Ozonoff, S., \& Hertz-Picciotto, I. (2015). Preeclampsia, placental insufficiency, and autism spectrum disorder or developmental delay. Jama Pediatrics, 169(2), 154-162. doi: 10.1001/ jamapediatrics.2014.2645

Xu, G., Jing, J., Bowers, K., Liu, B., \& Bao, W. (2014). Maternal diabetes and the risk of autism spectrum disorders in the off spring: a systematic review and meta-analysis. Journal of Autism and Developmental Disorders, 44(4), 766-775. doi: 10.1007/s10803-013-1928-2

Yuen, R. K., Thiruvahindrapuram, B., Merico, D., Walker, S., Tammimies, K., Hoang, N., ... Scherer, S.W. (2015). Wholegenome sequencing of quartet families with autism spectrum disorder. Nature Medicine, 21(2), 185-91. doi: 10.1038/nm.3792

Zanatta, E. A., Menegazzo, E., Guimarães, A. N., Ferraz, L., \& Motta, M. G. C. (2014). Cotidiano de famílias que convivem com o autismo infantil. Revista Baiana de Enfermagem, 28(3), 271-282. Recuperado de http://www.portalseer.ufba.br/index. php/enfermagem/article/view/10451/8989

Zanon, R.B., Backes, B., \& Bosa, C.A. (2014). Identificação dos primeiros sintomas do autismo pelos pais. Psicologia: Teoria e Pesquisa, 30(1), 25-33. doi:10.1590/S010237722014000100004 